\title{
DOES CULTURAL HERITAGE AFFECT JOB SATISFACTION? THE EAST-WEST DIVIDE
}

\author{
Nikica MOJSOSKA-BLAZEVSKI - Marjan PETRESKI - Venera KRLIU-HANDJISKI
}

(Received: 2 June 2013; revision received: 3 January 2014;

accepted: 5 April 2014)

\begin{abstract}
The objective of this paper is to examine the factors influencing workers' job satisfaction aside from the conventional factors, in the light of basic cultural values and beliefs, and then to set this into a comparative perspective for three groups of countries: South-East European (SEE) countries, Central and Eastern European countries (CEE) and Western Europe. Cultural values are grouped into traditional $v s$. secular-rational values and survival $v s$. self-expression values. The main result of the study is that culture has a considerable effect on job satisfaction across all groups of countries under investigation. However, there are between-group differences in terms of the relative importance of specific cultural values for job satisfaction. We also find some evidence suggesting the persistency of cultures and slow-moving institutions.
\end{abstract}

Keywords: job satisfaction, cultural values, culture convergence, South-East European countries

JEL classification indices: J28, J62, M14

Nikica Mojsoska-Blazevski, Full Professor and Dean of the Faculty of Business Economics and Management, School of Business Economics and Management, University American CollegeSkopje. E-mail: nikica@uacs.edu.mk

Marjan Petreski, corresponding author. Associate Professor at the School of Business Economics and Management, and Vice Rector for Research of the University American College-Skopje.

E-mail: marjan.petreski@uacs.edu.mk

Venera Krliu-Handjiski, Assistant Professor at the School of Business Economics and Management, University American College-Skopje. E-mail: vicepresident@uacs.edu.mk 


\section{INTRODUCTION}

Do workers in the Eastern, ex-communist countries share the same values and beliefs as citizens of Western countries? While economists are certain about the convergence in economic performance and the catch-up effect that Eastern countries experienced in their accession to the EU, there is still a small body of literature on the convergence of culture. In particular, there are two competing theories: the first, the so-called "modernisation theory", claiming that economic prosperity brings convergence in cultures, while the opposite one argues that traditional values persist despite economic and political progress (Inglehart - Baker 2000). Although almost two decades have passed since the collapse of communist regimes, which is sufficient time for any cultural convergence to the EU to take place, there are very few studies in this area to date. Drawing from those studies, we provide additional insights, given that we sub-divide Eastern countries into two groups: the Central and Eastern European countries (CEE) and South-East Europe (SEE). This division is intended to reveal any differences due to the different stages of economic development at which these regions are, the possible effect of the geographical proximity of the CEE countries to the Western European countries as compared to the SEE countries as well as the prolonged period of political instability in the SEE region, which might have slowed down the cultural convergence of these countries to the EU.

The theoretical background to job satisfaction is quite large and dates back to Evans (1969), Locke (1969), Schwab - Cummings (1970), and Wanous - Lawler (1972), while more recent contributions include, for instance, Erez (1994) and Constanza et al. (2012), both with further references. The literature has mainly focused on the influence of the work situation on job satisfaction, with only more recent studies addressing the effects of culture and individual disposition (Saari Judge 2004). Despite the emergence of a large body of multi-disciplinary literature investigating the determinants of job satisfaction, ranging from human resource management to sociology, psychology, labour economics, and so on, the issue of culture and its effect on workers' well-being has largely been neglected again (Fargher et al. 2008). Indeed, Mueller et al. (2009) argue that the cross-national examination of job satisfaction has to move beyond the sole investigation of the measurement equivalence of used measures, and to examine the influence of culture and values on different job satisfaction levels across countries (Wiese 2014).

In this regard, the aim of this study is twofold. First, we examine factors influencing workers' job satisfaction aside from conventional factors (such as personal background, individual labour market characteristics, organisational culture, and so on) and introduce the basic cultural values and beliefs. The latter are grouped into traditional $v s$. secular-rational values and survival $v s$. self-expression values. 
Second, we investigate the relative importance of culture for job satisfaction in the (old) EU countries, CEE, and SEE countries. This issue has not been investigated in SEE, which is the main contribution this paper makes.

We continue with a brief literature review on the current studies in the field of the convergence of cultures, and the impact of culture and values on job satisfaction. In Section 3 we explain data, and in Section 4 the methodology used. Section 5 presents and discusses the results, while Section 6 concludes.

\section{CULTURE, CONVERGENCE AND JOB SATISFACTION}

Culture can be defined as a set of interrelated values, attitudes, and behaviours that form a group's, an organisation's or a country's system of values (Mujtaba et al. 2009). Similarly, Guiso et al. (2006: 2) define culture as "customary beliefs and values that ethnic, religious and social groups transmit fairly unchanged from generation to generation". Both definitions claim that common culture is transferred from generation to generation in a mostly unchanged form, which implies that there is no convergence of culture and values among societies over time. The latter, however, is an issue over which there is no consensus in the literature.

In particular, there are two compelling theories about the convergence of cultures. The first, the modernisation theory, among whose most prominent representatives we find Karl Marx, argues that economic and political development brings the replacement of absolute norms and values with values that are rational, tolerant, based on trust, and result in wider societal participation. In other words, modern and developed countries show the future for less developed ones (Inglehart - Baker 2000). However, until the late $20^{\text {th }}$ century, modernisation was viewed as a process inherent to Western societies only. If this belief holds, the modernisation of non-Western societies, including the ex-communist countries (or transition economies), would only be possible if those countries discard their traditional culture and values, and implement Western culture and values believed to be superior. This also implies a convergence of the culture and values of the new EU member states and the candidate countries to the old EU (or the EU-15) countries. However, some Eastern countries, mainly in East Asia, outperformed their Western peers in certain economic dimensions, refuting thereby the assumption that Western societies are role models for the world.

The opposite school of thought argues that traditional values are persistent and independent of the broader economic and political changes (Roland 2005; Inglehart 2008). For instance, Roland (2005) asserts that culture, along with the values, beliefs, and norms, is among the "slow-moving" institutions in society, which are difficult to change and which impact the "fast-moving" institutions 
such as political and legal institutions. The implication of this approach is that there is no convergence of values towards some "dominant" model or set of values (present in modern or developed societies), and that traditional values have a perpetual effect on cultural changes caused by economic and/or political changes (Inglehart - Baker 2000).

On the other hand, the determinants of job satisfaction have been largely investigated in an empirical context. For instance, $\mathrm{Ng}$ et al. (2009) conducted a meta-analysis of 287 articles, examining the relationship between job satisfaction and job performance across cultures other than the US. They found that in cultures driven by individualism and masculinity, the relationship between job satisfaction and job performance is stronger. Inglehart - Baker (2000) and Inglehart (2008) used nation-level data for more than 40 societies from the World Values Survey and found persistent differences between values in low-income and high-income countries in the area of political, social, and religious norms and beliefs, hence questioning the modernisation theory of convergence. Based on these findings, the authors formulated two dimensions which reflect cross-national differences; (1) traditional vs. secular-rational values towards authority, and (2) survival vs. self-expression values. A society that has low tolerance for abortion and divorce, respects parental authority, attaches high importance to family life, and is relatively authoritarian and religious, is considered a traditional society. The secular-rational society/values emphasize the opposite. Survival values include preferring economic and physical security to self-expression and quality of life, traditional gender roles, distrust, and intolerance. These distinctions are well established in the research literature (see, for instance, Inglehart - Baker 2000). In addition, Fargher et al. (2008) argue that culture and beliefs do not only influence workers' job satisfaction, but have a broader importance, given that they affect economic behaviour as well. The cross-cultural differences (once rooted in religion) become a part of the (distinctive) national culture and persist over time, fuelled by the family, education, local society, cultural institutions, and media (Inglehart - Baker 2000; Fernandez - Fogli 2005; Guiso et al. 2006). Moreover, as Inglehart - Baker (2000) argue, economic development leads to changes in dominant values and beliefs, and, consequently, to a cultural change, but not necessarily to a cultural convergence.

While there is a growing body of multi-disciplinary literature investigating the determinants of job satisfaction, ranging from human resource management to sociology, psychology, labour economics, and so on, the issue of culture and its effect on workers' well-being has largely been neglected (Fargher et al. 2008). Moreover, our study (similarly to that of Fargher et al.) investigates how job satisfaction is affected by the broad cultural values of a society, rather than by the organisational culture, and hence adds to the current research literature, which 
is dominated by the latter. This holds even more for transition economies where little research has been conducted in the area of job satisfaction, or human values associated with the corresponding economic behaviour and job (Vecernik 2003). In addition, we are interested in the East-West divide, given the fairly recent transformation of Eastern societies. The transition brought new challenges to these countries and called for changes in many domains of their economic and social life such as the former attitudes towards employment, prevailing expectations about strong social protection, the preferences for non-intensive work, general tolerance of corruption, "mechanical acceptance of everything issued" from the top of the hierarchy, and so on (Sandholtz - Taagepera 2005; Vecernik 2006: 1221). Specifically in the field of work, there were two dichotomies: work was simultaneously a right and an obligation, and it had social and socialisation values. The social value was related to the obligation to work, while the socialisation functions to the job being a means for building social networks.

\section{DATA}

To pursue the objective of examining the role of culture for job satisfaction, the data of the fourth wave (2008) of the European Values Survey (EVS) are used. To our knowledge, this is the broadest survey of values relevant to the objectives of this study. The entire sample includes 47 countries. ${ }^{1}$ The creation of three country groups aims to reveal any differences between the groups due to the potential influences of, mainly, the communist legacy as well as the different stages of economic and political development at which these regions are, and it is consistent with the suggestion in the literature (Inglehart - Baker 2000) that post-communist economies are likely to be different cultural zones on the global cultural map. Moreover, we argue that the geographical proximity of the CEE countries to the Western European countries as compared to the SEE countries as well as the prolonged period of political instability in the SEE region resulted in further cultural differences between the CEE and SEE countries. This type of analysis seems suitable, given that we have the EVS wave of 2008, almost 20 years after the break-up of the communist regimes, which is sufficient to analyse whether or

The Western countries group includes Austria, Belgium, Denmark, Finland, France, Germany, Greece, Iceland, Ireland, Italy, Luxembourg, Netherlands, Norway, Portugal, Spain, Sweden, Switzerland, Great Britain and Northern Ireland. The Central and Eastern Europe (CEE) group includes Bulgaria, Czech Republic, Estonia, Hungary, Latvia, Lithuania, Poland, Romania, Slovak Republic and Slovenia (the new EU member states). The South-East Europe (SEE) group includes Albania, Bosnia and Herzegovina, Croatia, Montenegro, Serbia, Macedonia and Kosovo (the candidate and potential candidate EU member states). 
not cultural convergence has occurred in those countries over the preceding two decades.

However, there might be some methodological problems when analysing job satisfaction and work values in general, given that all measures of values and satisfaction are obtained indirectly, through opinion or perception surveys (Blanchflower - Freeman 1997; Vecernik 2003). For instance, researchers have to accept the self-reported job satisfaction as a reliable measure for one's job satisfaction. In addition, the data collection can undermine the comparative research, given that cultural differences might lead to a different understanding of the same questions and concepts across countries. In the same line of argument, the different "survey literacy" of the population would lead to an international inconsistency of the data. Besides these methodological caveats, the data from EVS are generally accepted and used by researchers around the globe in comparative studies in different areas, although with some delayed interest by economists.

The dependent variable we include is job satisfaction as an ordered categorical variable where 1 reflects complete job dissatisfaction, while 10 complete job satisfaction (Table 1). This variable corresponds to the question "Overall, how satisfied or dissatisfied are you with your job? "Note that measured this way, job satisfaction might reflect the satisfaction with a specific job contract or a workplace. However, we treat it as representing job satisfaction in general, despite the warning of Georgellis - Lange (2007a) that the latter might differ from the former because such a distinction is not available in the EVS. A concern might be raised over "the use of single-item measures of complex attitude structures" (Georgellis - Lange 2007b: 7), since values in the EVS are measured and approximated by a single question. However, Wanous et al. (1997) use a meta-analysis of job satisfaction studies and find that single-item measures can be used in job satisfaction studies without that being considered as a flaw.

\section{METHODOLOGY}

Since the dependent variable is an ordered categorical variable, ordered probit regression will be used (McKelvey - Zavoina 1975). Within the regression, it is assumed that a latent and continuous measure of the dependent variable $S_{i}^{*}$ follows the normal distribution with $\mu_{i}$ mean and unitary variance. It is defined as:

$$
\mathrm{S}_{\mathrm{i}}^{*}=\beta^{*} \mathrm{z}_{\mathrm{i}}+\mathrm{e}_{\mathrm{i}}
$$

where $z_{\mathrm{i}}$ is a vector of explanatory variables describing individual characteristics, $\beta$ is the vector of parameters to be estimated, and $e_{i}$ is the random error which is assumed to be well-behaved. Then, the observation mechanism is: 
Table 1

Data

\begin{tabular}{|c|c|}
\hline Variable & Description \\
\hline Job satisfaction & $\begin{array}{l}\text { Ordered categorical variable on a scale } \\
1 \text { to } 10(1=\text { extremely dissatisfied; } 10= \\
\text { extremely satisfied })\end{array}$ \\
\hline Sex & Dummy: $1=$ male $; 0=$ female \\
\hline Age & Continuous variable in years \\
\hline Single (Reference category) & Dummy: $1=$ single; $0=$ otherwise \\
\hline Married & $\begin{array}{l}\text { Dummy: } 1=\text { married/registered partnership; } \\
0=\text { otherwise }\end{array}$ \\
\hline Widowed & Dummy: $1=$ widowed; $0=$ otherwise \\
\hline Divorced & Dummy: $1=$ divorced $/$ separated; $0=$ otherwise \\
\hline Lower education (Reference category) & Dummy: $1=$ primary school; $0=$ otherwise \\
\hline Middle education & Dummy: $1=$ secondary school; $0=$ otherwise \\
\hline Upper education & $\begin{array}{l}\text { Dummy: } 1=\text { tertiary school and above; } \\
0=\text { otherwise }\end{array}$ \\
\hline Low income (Reference category) & $\begin{array}{l}\text { Dummy: } 1=\text { annual income below } \\
24.000 \text { EUR; } 0=\text { otherwise }\end{array}$ \\
\hline Middle income & $\begin{array}{l}\text { Dummy: } 1=\text { annual income above } 24.000 \text { EUR } \\
\text { but below } 60.000 \text { EUR; } 0=\text { otherwise }\end{array}$ \\
\hline High income & $\begin{array}{l}\text { Dummy: } 1=\text { annual income above } \\
60.000 \text { EUR; } 0=\text { otherwise }\end{array}$ \\
\hline \multicolumn{2}{|c|}{ Traditional vs. Secular-Rational Values } \\
\hline Importance of work & $\begin{array}{l}\text { Dummy: } 1=\text { work is very or quite important; } \\
0=\text { otherwise }\end{array}$ \\
\hline Importance of religion & $\begin{array}{l}\text { Dummy: } 1=\text { religion is very or quite } \\
\text { important; } 0=\text { otherwise }\end{array}$ \\
\hline Importance of family & $\begin{array}{l}\text { Dummy: } 1=\text { family is very or quite important } \\
0=\text { otherwise }\end{array}$ \\
\hline Would never sign a petition & $\begin{array}{l}\text { Dummy: } 1=\text { have signed a petition; } 0=\text { might } \\
\text { do or never did }\end{array}$ \\
\hline \multicolumn{2}{|c|}{ Survival values vs. Self-Expression Values } \\
\hline Has to be careful when trusting people & $\begin{array}{l}\text { Dummy: } 1=\text { cannot be too careful when } \\
\text { trusting people; } 0=\text { otherwise }\end{array}$ \\
\hline A woman has to have children to be fulfilled & $\begin{array}{l}\text { Dummy: } 1=\text { thinking woman needs child for } \\
\text { fulfilment; } 0=\text { otherwise }\end{array}$ \\
\hline Job security is an important aspect of job & $\begin{array}{l}\text { Dummy: } 1=\text { job security is an important aspect } \\
\text { of a job; } 0=\text { otherwise }\end{array}$ \\
\hline $\begin{array}{l}\text { Tolerance and respect not the most important } \\
\text { things to teach a child }\end{array}$ & $\begin{array}{l}\text { Dummy: } 1=\text { consider tolerance/respect for } \\
\text { others not important to teach a child; } \\
0=\text { otherwise }\end{array}$ \\
\hline Homosexuality is never justifiable & $\begin{array}{l}\text { Ordered categorical variable on a scale } 1 \text { to } 10 \\
(1=\text { homosexuality always justifiable; } \\
10=\text { homosexuality never justifiable })\end{array}$ \\
\hline
\end{tabular}




$$
\mathrm{S}_{\mathrm{i}}=\mathrm{j} \text { if } \tau_{\mathrm{j}}-1 \leq \mathrm{S}_{\mathrm{i}}^{*} \leq \tau_{\mathrm{j}}
$$

For $\mathrm{j}=1, \ldots, \mathrm{J}$, where $\mathrm{J}$ is the total number of categories.

Given the constraints $v_{1}<\tau$ for all $1<\mathrm{m}$ and $\tau_{0}=-\infty$ and $\tau_{j}=+\infty$, it follows that the observed and coded discrete dependent variable $\mathrm{S}_{\mathrm{i}}$ is determined from the model as follows:

$$
S_{i}=\left\{\begin{array}{lll}
1 & \text { if } & -\infty \leq S_{i}^{*} \leq \tau_{1} \\
2 & \text { if } & \tau_{1} \leq S_{i}^{*} \leq \tau_{2} \\
10 & \text { if } & \tau_{9} \leq S_{i}^{*} \leq+\infty
\end{array}\right.
$$

where $\tau_{i}$, for $\mathrm{i}=1, \ldots, \mathrm{J}$, represents thresholds to be estimated along with the parameter vector $\beta$.

The probability for each category is given by:

$$
\operatorname{Pr}\left(S_{i}=j\right)=\varphi\left(\tau_{j} \mid \mu_{i}\right)-\varphi\left(\tau_{j-1} \mid \mu_{i}\right), \text { with } j=1, \ldots, J .
$$

where $\varphi\left(\mu_{i}\right)$ is the cumulative distribution function for the normal distribution with mean $\mu_{i}$ and unitary variance. Note that the interpretation of this regression in this paper is based primarily on the coefficients and, hence, mainly accounts for the sign and statistical significance rather than for the calculated marginal effects. Positive signs for the estimated parameters indicate higher levels of job satisfaction as the value of the associated variable increases. With a decreasing value of the associated variable, a negative sign for the coefficients suggests the opposite.

\section{RESULTS AND DISCUSSION}

Our results in Table 2 suggest that males are less satisfied with their job in the CEE region, with the coefficient being similar to and not statistically different than that in Western Europe, but no such differentiation for SEE can be inferred, given the insignificant coefficient. The importance of age for job satisfaction varies across the groups of countries. In particular, age is important for job satisfaction in SEE, but not in CEE. SEE results are in line with those of the Western countries. Moreover, a squared term is included to control for a convex relationship, which Clark et al. (1996) attribute to the personal circumstances under which individuals live, the life stage at which they are, as well as the factors outside employment that might affect job satisfaction. However, in all cases, the 
rising job satisfaction with age after the turning point is likely to be small, given the small estimated coefficient.

In all groups, marital status plays a significant role in job satisfaction, suggesting that married people are more satisfied with their job compared to single people. Between groups, the satisfaction with marriage is likely to be higher in SEE than both in CEE and Western Europe, which may be due to the perception of marriage in SEE as reflecting stability in life. While the latter could not be supported by the tests for statistical difference of the coefficients, it may be supported by the significant coefficient of the variable for divorced persons in Western countries. Namely, the status of the divorced is still considered a taboo topic in SEE societies, especially in smaller communities, while in Western societies as being more of a normal nature. Therefore, the coefficient in the Western countries is positive, while it is negative in SEE (despite being insignificant).

Educational level is highly significant in all cases. Results suggest that the higher the educational level, the more satisfied people are with their job; however, these satisfaction-differentials with the educational level are pronounced in $\mathrm{CEE}$ and even more so in SEE. In addition, the test for statistical differences confirm that higher education in CEE and SEE produces higher job satisfaction than in the Western world, most likely owing to the communist past when the planned economy had allocated individuals to job places not necessarily associated with their educational level or type. When it comes to income level, similarly as with education, the higher the income level, the higher the job satisfaction, but coefficients between groups are statistically insignificant. The only exception is SEE, where, if the earner belongs to the high income group, no statistical difference in job satisfaction can be inferred as compared to the base group. This can be attributed to the increased income inequality in SEE, where only a small fraction of employees belongs to the high income group.

Turning to the variables which are of primary interest to this paper, we conclude that cultural values are of importance for workers' job satisfaction in all regions. Our results are consistent with the findings of Fargher et al. (2008) for Western Europe and CEE, suggesting that cultural values are reluctant to change in the short run (Fargher et al. base their analysis on a previous EVS wave, conducted several years ago). This can be regarded as an indirect but cautious support of the theory asserting that culture, along with the values, beliefs, and norms, is among the "slow-moving" institutions of society, which are difficult to change (Roland 2005). Work is found to be important for job satisfaction. However, on average, work is less important in CEE than in the West, and less important in SEE than in CEE and the West (but without statistical difference between the latter two). The greater importance of work for job satisfaction in the West than in the East might be explained with the role that other factors have 
Table 2

Baseline results

\begin{tabular}{|c|c|c|c|c|}
\hline \multirow[t]{2}{*}{$\begin{array}{l}\text { Dependent variable - } \\
\text { job satisfaction }\end{array}$} & All countries & $\begin{array}{l}\text { Western } \\
\text { countries }\end{array}$ & CEE & SEE \\
\hline & (1) & (2) & (3) & (4) \\
\hline Sex $($ male $=1)$ & $-0.027 * *$ & $-0.048 * * *$ & $-0.051 * *$ & 0.011 \\
\hline Age (years) & $-0.023^{* * *}$ & $-0.035 * * *$ & -0.010 & $-0.031 * * *$ \\
\hline Age-squared & $0.000 * * *$ & $0.000 * * *$ & $0.000^{*}$ & $0.000 * *$ \\
\hline \multicolumn{5}{|c|}{ Marital status $($ reference $=$ single $)$} \\
\hline Married & $0.083 * * *$ & $0.105 * * *$ & $0.076^{* *}$ & $0.135^{* * *}$ \\
\hline Widowed & -0.010 & 0.076 & 0.108 & -0.010 \\
\hline Divorced & 0.032 & $0.065 *$ & -0.030 & -0.073 \\
\hline \multicolumn{5}{|c|}{ Level of education (reference $=$ lower education) } \\
\hline Middle education & $0.073 * * *$ & $0.089 * * *$ & $0.214 * * *$ & $0.167^{* * *}$ \\
\hline Upper education & $0.159^{* * *}$ & $0.078 * * *$ & $0.355^{* * *}$ & $0.499 * * *$ \\
\hline \multicolumn{5}{|c|}{ Income level (reference $=$ low income) } \\
\hline Middle income & $0.215^{* * *}$ & $0.133 * * *$ & $0.115^{* * *}$ & $0.267^{* * *}$ \\
\hline High income & $0.252 * * *$ & $0.225 * * *$ & $0.205^{* * *}$ & -0.024 \\
\hline \multicolumn{5}{|c|}{ Cultural values (traditional vs. secular) } \\
\hline Importance of work & $0.413 * * *$ & $0.534 * * *$ & $0.317 * * *$ & $0.287 * *$ \\
\hline Importance of religion & $0.086^{* * *}$ & $0.094 * * *$ & $0.065^{* *}$ & $0.173^{* * *}$ \\
\hline Importance of family & -0.035 & $0.119 *$ & -0.011 & $-0.385^{* *}$ \\
\hline Would never sign a petition & $0.034 * * *$ & -0.002 & $0.051^{*}$ & -0.037 \\
\hline \multicolumn{5}{|c|}{ Cultural values (survival vs. self-explanatory) } \\
\hline $\begin{array}{l}\text { Has to be careful when trusting } \\
\text { people }\end{array}$ & $-0.086^{* * *}$ & $-0.132 * * *$ & $-0.113^{* * *}$ & $-0.165^{* * *}$ \\
\hline $\begin{array}{l}\text { A woman has to have children to } \\
\text { be fulfilled }\end{array}$ & $-0.058^{* * *}$ & $-0.033^{*}$ & $-0.059 * *$ & $-0.062 *$ \\
\hline $\begin{array}{l}\text { Job security is an important aspect } \\
\text { of job }\end{array}$ & $0.045^{* * *}$ & 0.021 & -0.033 & $0.155^{* * *}$ \\
\hline $\begin{array}{l}\text { Tolerance and respect not the most } \\
\text { important things to teach a child }\end{array}$ & $0.026^{*}$ & 0.028 & -0.001 & -0.019 \\
\hline Homosexuality is never justifiable & $0.007 * * *$ & $0.008^{* *}$ & -0.007 & -0.010 \\
\hline Observations & 26,354 & 10,895 & 5,756 & 3,831 \\
\hline Pseudo $R$-square & 0.652 & 0.821 & 0.554 & 0.662 \\
\hline /cut1 & -1.86 & -2.09 & -1.91 & -2.48 \\
\hline /cut2 & -1.63 & -1.85 & -1.66 & -2.26 \\
\hline /cut3 & -1.33 & -1.53 & -1.33 & -1.95 \\
\hline /cut4 & -1.07 & -1.26 & -1.09 & -1.67 \\
\hline /cut5 & -0.65 & -0.88 & -0.65 & -1.19 \\
\hline /cut6 & -0.34 & -0.55 & -0.32 & -0.88 \\
\hline /cut7 & 0.11 & -0.02 & 0.13 & -0.51 \\
\hline /cut8 & 0.75 & 0.73 & 0.76 & 0.02 \\
\hline /cut9 & 1.23 & 1.33 & 1.21 & 0.40 \\
\hline
\end{tabular}

Notes: $* * *$ and ${ }^{* * *}$ indicate significance at the 10,5 and $1 \%$ level, respectively. All estimators are ordered probit. 
for job satisfaction in the societies of Eastern Europe such as religion, family, and friend ties. Overall, though, as in Fargher et al. (2008), the effect of work on job satisfaction is stronger than the effect of income, which questions the current motivational activities (measures) of managers. As expected, religion is found to be more important in SEE than in CEE and in the West. This is also confirmed by the statistical tests and could be attributed to the higher religiousness of SEE societies, despite their higher heterogeneity (usually mixtures of Catholics, Orthodox and Muslims) vis-à-vis Western and CEE societies, which are predominantly Catholic. Important cultural differences could be important for the relationship between family and job satisfaction. If a person considers family as quite important, then his/her job satisfaction is higher on average. The opposite is found in SEE, where if family is considered important in life, then job satisfaction is lower, which could be attributed to the priority that SEE societies give to family at the expense of a job, especially among females. In contrast, more mature societies are more likely to try and to establish a balance between family and work. In this respect, CEE may be in the middle (switching from treating family at the expense on work to balancing them), so this may justify the insignificance of the coefficient. The results on "petition singing" are generally insignificant or with significance on the margin.

In the survival $v s$. self-explanatory group of cultural values, some diversity is again observed across groups of countries. The more cautious people are when trusting others, the more satisfied they are with their job, with the coefficient between groups being likely similar (coefficients are not statistically different between groups of countries). Hence, in line with Fargher et al. (2008), interpersonal trust serves as a particularly strong predictor of job satisfaction for both Eastern and Western Europe. The belief that a woman needs a child to be fulfilled reduces job satisfaction, which is expected, given the satisfaction extracted from bearing and raising a child. Job security is only significant in SEE, suggesting that if people place a high value on job security, then they are more satisfied with their job. The significance in SEE might be only a result of the fragile labour markets in those countries, whereby losing a job is associated with large personal and social losses. Teaching tolerance and respect to children is not an important determinant of job satisfaction, while the justification of homosexuality is only relevant in the Western world, expectedly, given the conservative attitude that Eastern countries have (had) towards homosexuality. 


\section{CONCLUSION}

The objective of this paper has been to examine the factors influencing workers' job satisfaction aside the conventional factors (personal background, individual labour market characteristics, organisational culture, and so on), to introduce the basic cultural values and beliefs, and then to put this into a comparative WestEast perspective, the East being further divided as Central vs. South-East Europe. Cultural values have been grouped into traditional vs. secular-rational values and survival $v s$. self-expression values. The main result of the study is that cultural heritage exerts a considerable impact on job satisfaction across all groups of countries under investigation. There are, however, between-group differences in terms of the particular cultural values that affect job satisfaction as well as the size of the effect. In particular, we find that the importance of the traditional $v s$. secularrational values is greater in SEE, followed by CEE. This holds especially true for the importance of religion and family. Having work, however, is most important in the West, followed by CEE, and least important in SEE. Within the survival vs. self-expression values, the difference arises for the effect of job security on job satisfaction (only significant in SEE) and the justification of homosexuality (only important in the Western world). Our study also finds some evidence suggesting the persistency of culture and slow-moving institutions.

\section{REFERENCES}

Blanchflower, D.G. - Freeman, R.B. (1997): The Attitudinal Legacy of Communist Labour Relations. Industrial and Labour Relational Review, 50(3): 438-459.

Clark, A.E. - Oswald, A. - Warr, P. (1996): Is Job Satisfaction U-Shaped in Age? Journal of Occupational and Organizational Psychology, 69(1): 57-81.

Costanza, D. - Badger, J. - Fraser, R. - Severt, J. - Gade, P. (2012): Generational Differences in Work-Related Attitudes: A Meta-Analysis. Journal of Business \& Psychology, 27(4): 375-394.

Erez, M. (1994): Towards a Model of Cross-Cultural I/O Psychology. In: Dunnette, M.D. - Hough, L. - Trianidis, H. (eds): Handbook of Industrial and Organizational Psychology (2 ${ }^{\text {nd }}$ Edition), Palo Alto, Ca: Consulting Psychologists Press, pp. 596-607.

Evans, M.G. (1969): Conceptual and Operational Problems in the Measurement of Various Aspects of Job Satisfaction. Journal of Applied Psychology, 53: 93-101.

Fargher, S. - Kesting, S. - Lange, T. - Pacheco, G. (2008): Cultural Heritage and Job Satisfaction in Eastern and Western Europe. International Journal of Manpower, 29(7): 630-650.

Fernandez, R. - Fogli, A. (2005): Culture: An Empirical Investigation of Beliefs, Work and Fertility. Staff Report, No. 361, Federal Reserve Bank of Minneapolis Research Department.

Georgellis, Y. - Lange, T. (2007a): Participation in Continuous, On-the-Job Training and the Impact on Job Satisfaction: Longitudinal Evidence from the German Labour Market. International Journal of Human Resource Management, 18(6): 969-985. 
Georgellis, Y. - Lange, T. (2007b): Traditional vs Secular Values and Work-Life Balance across Europe. Paper presented at the 2007 ISQOLS Conference, San Diego, CA.

Guiso, L. - Sapienza, P. - Zingales, L. (2006): Does Culture Affect Economic Outcomes? NBER Working Paper Series, No. 11999.

Inglehart, R. (2008): Changing Values among Western Publics between 1970 and 2006. West European Politics, 31(1-2): 130-146.

Inglehart, R. - Baker, W.E. (2000): Modernization, Cultural Change, and the Persistence of Traditional Values. American Sociological Review, 65(1): 19-51.

Locke, E.A. (1969): What is Job Satisfaction? Organizational Behavior and Human Performance, 4: 309-336.

McKelvey, R. - Zavoina, W. (1975): A Statistical Model for the Analysis of Ordinal Level Dependent Variables. Journal of Mathematical Sociology, 4(1): 103-120.

Mujtaba, B.G. - Murphy, E.F. - McCartney, T. - Williams, A. - Trumbach, A. - Reid, J. - Greenwood, R. - Teeple, W. - Woodhol, M.D. (2009): Convergence and Divergence of Values and Type A Behaviour Patterns between Developing and Developed Countries. The Icfai University Journal of Organizational Behavior, VIII(2): 6-34.

Ng, T.W.H. - Sorensen, K.L. - Yim, F.H.K. (2009): Does the Job Satisfaction - Job Performance Relationship Vary Across Cultures? Journal of Cross-Cultural Psychology, 40(5): 761-796.

Roland, G. (2005): Understanding Institutional Change: Fast-Moving and Slow-Moving Institutions. Working Paper. Available on-line at http://www.econ.berkeley.edu/ groland/pubs/gr3.pdf

Saari, L.M. - Judge, T.A. (2004): Employee Attitudes and Job Satisfaction. Human Resource Management, 43(4): 395-407.

Sandholtz, W. - Taagepera, R. (2005): Corruption, Culture, and Communism. International Review of Sociology, 15(1): 109-131.

Schwab, D.P. - Cummings, L.L. (1970): Employee Performance and Satisfaction with Work Roles: A Review and Interpretation of Theory. Industrial Relations, 9: 408-430.

Togler, B. (2003): Tax Morale: Theory and Empirical Analysis of Tax Compliance. Unpublished $P h D$ dissertation. Universität Basel.

Vecernik, J. (2003): Skating on Thin Ice: A Comparison of Work Values and Job Satisfaction in CEE and EU Countries. International Journal of Comparative Sociology, 44(5): 444-471.

Vecernik, J. (2006): Work Values and Job Attitudes in the Czech Republic between 1997 and 2005. Czech Sociological Review, 42(6): 1219-1240.

Wanous, J.P. - Lawler, E.E. (1972): Measurement and Meaning of Job Satisfaction. Journal of Applied Psychology, 56(2): 95-105.

Wanous, J. - Reichers, A. - Hudy, M. (1997): Overall Job Satisfaction: How Good are Single-Item Measures? Journal of Applied Psychology, 82(2): 247-252.

Wiese, T. (2014): Analysis of the Trend Growth of GDP and Life Satisfaction in the EU. Acta Oeconomica, 64(4): 511-524 